\title{
AIAA 98-0549 \\ SHOCK-INDUCED DETONATION WAVE DRIVER FOR ENHANCING SHOCK TUBE PERFORMANCE
}

\author{
W. S. Stuessy* F. K. Lu ${ }^{\dagger}$ and D. R. Wilson ${ }^{\ddagger}$ \\ Aerodynamics Research Center \\ The University of Texas at Arlington \\ Arlington, Texas 76019
}

\begin{abstract}
$\underline{\text { Abstract }}$
An existing pressure-driven hypersonic shock tunnel at the University of Texas at Arlington (UTA) was converted to a detonation-driven shock tube. The specific goal was to create a test environment to investigate electrical properties of high-pressure seeded air plasmas to support development of a test facility concept involving the use of MHD augmentation of high-pressure arc heaters for hypersonic engine testing. The existing shock tunnel is described along with the modifications for conversion to the detonationdriven mode of operation. Experimental performance data are presented for both electric arc-induced and shock-induced detonation modes of operation. The detonation driver will be a permanent addition to the shock tunnel facility, and estimates of the performance improvement for the detonation-driven mode of operation are presented.
\end{abstract}

\section{Introduction}

The University of Texas at Arlington supported MSE, Inc. in a NASA-sponsored program to investigate the use of MHD augmentation of highpressure arc heaters to provide a new ground test facility for hypersonic propulsion system testing. A critical issue associated with the development of this concept is the need for experimental validation of theoretical methods for calculating the electrical conductivity of high-pressure seeded-air plasmas.

\footnotetext{
-Faculty Research Associate. Aerodynamics Research Center, Senior Member.

'Associate Professor of Aerospace Engineering and Director. Aerodynamics Research Center, Associate Fellow.

'Professor and Chairman, Department of Mechanical and Aerospace Engineering, Associate Fellow.

Copyright (c) 1998 by the American Institute of Aeronautics and Astronautics, Inc. All rights reserved.
}

Measurements of electrical conductivity have been reported in the literature $e^{1,2}$, but generally at pressure levels considerably below those required for the current facility concept. A preliminary investigation of the proposed MHD-augmented test facility concept indicated that accelerator entrance conditions on the order of Mach 2 at pressures of 10 to $100 \mathrm{~atm}$ and temperatures of 2200 to $4000 \mathrm{~K}$ were required $^{3}$. These test conditions were beyond the capability of the existing UTA pressure-driven shock tunnel, and a development program to upgrade the performance of the facility was funded by MSE. A number of options were considered including addition of an external heater to the driver tube ${ }^{4}$, and incorporation of the free-piston driver concept $^{5}$. Modification of the existing shock tunnel to a detonation-driven shock tube $e^{6-8}$ appeared to be the most cost-effective approach to generate this test environment.

The benefits of the detonation driver include production of a driver gas, upon detonation, that has high pressure, high temperature, low molecular weight, low specific heat ratio, and a high speed of sound. The initial pressure of the gaseous mixture is quite low, reducing the need for high-pressure equipment to pressurize the driver. The high temperature generated is for very short periods of time so the driver structure is not exposed to high temperature. The design is thereby reduced to one of pressure containment. Disadvantages are the dangers involved with the explosive mixture and the requirement for an ignition source. The danger of the explosive mixture can be reduced by helium dilution. Helium dilution does not substantially degrade performance and in certain situations actually allows more control of the temperature generated in the driver. The molecular weight of the driver gas is reduced by helium dilution, which is a beneficial effect. The addition of helium does slightly increase the energy required to initiate the detonation. 


\section{Facility Design and Performance Analysis}

The detonation driver can be operated in two modes. In the downstream-propagation mode, the ignition source is located at the upstream end of the driver to generate a downstream-propagating detonation that ruptures the diaphragm upon impact. A wave diagram illustrating this mode is shown in Fig. 1. The gas behind the reflected detonation (region 4") initiates the incident shock wave in the driven tube. In the upstreampropagation mode (Fig. 2), the ignition source is located at the downstream end of the driver near the diaphragm. This concept uses the pressure rise generated by the upstream-propagating detonation wave to rupture the diaphragm and initiate the incident shock wave in the driven tube. The detonation wave will travel upstream towards the closed end of the driver, then reflect as shown in Fig. 2. The pressure behind the reflected detonation wave must be kept below the pressure limit of the driver.

Preliminary performance estimates for the downstream-propagation mode are shown in Fig. 3 for a driver-to-driven tube area ratio of 13.65 . These calculations were made with a Windows version of the NASA CEC76 code ${ }^{9}$. The shock tube performance calculations were based on an equilibrium flow assumption. The CEC code was first used to calculate detonation tube performance for stoichiometric mixtures of hydrogen and oxygen, for a range of initial pressures and different amounts of helium dilution. An existing perfect gas code ${ }^{10}$ calculated the driven-tube pressure ratio $p_{2} / p_{1}$ and shock speed as a function of the shock tube pressure ratio $\left(p_{4}{ }^{\prime \prime} / p_{1}\right.$ for the upstream mode or $p_{4}{ }^{\prime} / p_{1}$ for the downstream mode), gas properties, and shock tube area ratio. The CEC code was then used to calculate the temperature ratio across the incident shock wave using the perfect gas value of shock speed. The performance envelope was obtained for a stoichiometric oxygen and hydrogen mixture at initial driver pressures ranging from 1 to $8 \mathrm{~atm}$ and a driven tube filled with air at initial pressure from 0.063 to $10 \mathrm{~atm}$. The initial gas temperature was $300 \mathrm{~K}$. Also included for comparison are the performance maps of cold air and cold helium drivers, with the driver operated at its maximum rating of $400 \mathrm{~atm}$. The downstream mode of operation was initially selected since test conditions behind the driven-tube incident shock wave in excess of $100 \mathrm{~atm}$ and $4000 \mathrm{~K}$ were predicted for this mode. The upstream mode resulted in pressure levels behind the reflected detonation wave in excess of the 400-atm pressure rating of the driver tube to produce comparable test conditions.

\section{Facility Description}

The existing shock tunnel facility ${ }^{11}$ is shown schematically in Fig. 4. The shock tube is composed of a $15.24 \mathrm{~cm}$ (6 in) diameter, $3 \mathrm{~m}$ (10 ft) long driver tube, and a $15.24 \mathrm{~cm}$ (6 in) diameter, $8.23 \mathrm{~m}(27 \mathrm{ft})$ long driven tube. A double-diaphragm section separates the driver and driven tubes. Both tube sections are rated for a pressure of $41.3 \mathrm{MPa}(6000 \mathrm{psi})$. The diaphragms are normally constructed from 10 or 12 gauge ( 3.42 or $2.66 \mathrm{~mm}$ ) hot-rolled 1008 steel plates, scored to various depths in a cross pattern. A $7.5^{\circ}$ half-angle conical nozzle with interchangeable throat inserts for Mach numbers of 5 to 16 is attached to the end of the driven tube. The exit diameter of the nozzle is $33.6 \mathrm{~cm}$ (13.25 in). Previous operation of the shock tunnel employed the reflected-mode of operation, with the nozzle configured for Mach 8. A secondary diaphragm constructed from $0.0127 \mathrm{~mm}$ (0.005 in) thick aluminum sheet was located in the nozzle throat region, and used to separate the driventube gas from that in the test section. The test section is a semi-free jet design, $53.6 \mathrm{~cm}(21.1 \mathrm{in})$ long and $44.0 \mathrm{~cm}(17.5 \mathrm{in})$ in diameter. Two 23 $\mathrm{cm}$ (9 in) diameter optical windows are located on opposite sides of the test section. The diffuser is $30.5 \mathrm{~cm}$ (12 in) in diameter, $213 \mathrm{~cm}$ (84 in) long and connects the test section to a $4.25 \mathrm{~m}^{3}$ (150 $\mathrm{ft}^{3}$ ) vacuum tank. The test section and diffuser contain model mounting and instrumentation ports.

The pneumatic system consists of a Haskell model 55696 two-stage gas-driven booster pump capable of charging the driver tube to $41.3 \mathrm{MPa}$ (6000 psi). The Haskell pump is normally connected to the facility air compressor system, consisting of a Clark CMB-6 5-stage air compressor, twin-tower desiccant drier and 14.5 MPa (2100 psi) storage bottles. Alternatively, the Haskell pump can be fed from a manifold of 15.2 MPa (2200 psi) helium storage bottles. The vacuum system consists of a Sargent-Welch model $1376(300 \mathrm{l} / \mathrm{min})$ pump used to evacuate the driven tube, a Sargent-Welch model 1396 (2800 $\mathrm{l} / \mathrm{min})$ pump used to evacuate the test section/diffuser/vacuum tank, and a vacuum pressure measurement system consisting of two Baratron type 127A pressure transducers and the 
associated valve system to enable full range coverage from 1000 to 0.001 Torr.

\section{Detonation Driver}

The driver from the existing shock tunnel was modified to serve as the detonation driver. Four surface mounted pressure transducers were installed to monitor the behavior of the detonation wave. Ports were also installed for inserting an ignition plug at either end of the tube so that both upstream and downstream-propagation modes could be evaluated. Two existing ports were used for injecting hydrogen, oxygen and helium as well as for evacuating the tube and venting the combustible mixture in case of an aborted run. The conversion to a detonation driver retained the same pressure rating.

\section{Driven Tube}

The original driven tube was replaced with a new tube of type 304 stainless steel, with a $4.12 \mathrm{~cm}$ (1.62 in) internal diameter that was $9 \mathrm{~m} \mathrm{(30} \mathrm{ft)} \mathrm{in}$ length. The tube was commercially available and had a pressure rating of $19 \mathrm{MPa}$ (2800 psi). The detonation-driven shock tube was designed for operation in the non-reflected mode for the MSE test program; thus the driven tube could be designed for a lower pressure rating. The existing downstream diaphragm section and hypersonic nozzle were removed, and the end of the driven tube was extended into the existing vacuum tank. The tank was not used for vacuum but for collection of the exhaust gases before releasing them to atmosphere. This combination of driver and driven tube produced a driver-to-driven tube area ratio of 13.65 that provides an additional improvement in performance.

\section{Pneumatic Injection System}

The hydrogen, oxygen, and helium are injected through the sidewall of the driver. Two tubes are available for this purpose. The hydrogen and oxygen are injected through separate tubes for safety purposes. Helium and purge air is injected through the oxygen line. The initial air is evacuated through the hydrogen line and the combustible mixture is also vented through the hydrogen line. The two lines also contain Matheson series 6103 flash arrestors for added safety.

\section{Instrumentation/Data Acquisition System}

The detonation driver instrumentation includes four PCB model 111A22 dynamic pressure transducers and a MKS model 127A Baratron pressure transducer. The Baratron transducer has a maximum pressure range of $1.33 \mathrm{MPa}(10000$ Torr), and was used to set the mixture ratio during filling of the detonation driver by setting the proper partial pressures. The PCB transducers are mounted in the driver tube with the sensing diaphragm flush with the inside wall. Each one has a full-scale range of $68.9 \mathrm{MPa}(10000 \mathrm{psi})$, rise time of $2 \mu \mathrm{s}$, and a time constant of $1000 \mathrm{~s}$. The Baratron is used to provide an initial pressure reading for the PCB dynamic transducers.

The driven tube instrumentation also includes four PCB transducers. Two PCB model 111A23 transducers, which have a full scale pressure range of $34.4 \mathrm{MPa}$ (5000 psia), rise time of $2 \mu \mathrm{s}$, and a time constant of $500 \mathrm{~s}$, are used primarily for shock speed measurements as they are upstream of the test area and separated by a precisely measured distance. The other two PCB transducers are either models 111A23 or 111A24, depending upon the conditions in the driven tube. The model 111A24 transducers have a full-scale range of $6.89 \mathrm{MPa}$ (1000 psia), a response time of $2 \mathrm{kS}$, and a time constant of $100 \mathrm{~s}$. A MKS model 127A Baratron pressure transducer also measures the initial pressure in the driven tube. This transducer has a maximum pressure range of 133 $\mathrm{kPa}$ (1000 Torr), and provides a very accurate measurement of the initial driven tube pressure. It also provides an initial reference pressure for the PCB dynamic pressure transducers.

The pressure transducers were connected to a DSP Technology, 48-channel data acquisition system. Each channel can be sampled at rates up to $100 \mathrm{kHz}$, and has a dedicated amplifier and 12bit analog to digital converter. The system has 512 kilosamples of memory available for distribution between the channels being utilized. Eight 12 bit, $1 \mathrm{MHz}$ channels are also available. Two megasamples of memory are available for these eight channels. A PC that retrieves the data through an IEEE-488 interface bus controls the data acquisition system. The data are then stored on the PC harddrive for later analysis.

The pressure transducers provide direct measurement of pressure ratios upon passage of both the detonation and shock waves. Furthermore, time-of-flight measurements were used to calculate wave propagation speeds by determining the time between passage of the 
detonation or shock wave between successive transducers. Since the transducers are a known distance apart, the shock or detonation velocity can be determined from the measured time interval befween adjacent pressure transducers. This provided an important indication of the properties of the detonation wave; primarily that the wave had indeed transitioned to a fully developed Chapman-Jouguet wave.

\section{Experimental Test Program}

\section{Arc-Induced Detonation Mode}

The initial operation of the modified shock tube consisted of a series of test runs at increasing pressure levels to verify the design and refine operating procedures. The first test run was with a stoichiometric mixture of hydrogen and oxygen in the driver at an initial pressure of 1 atm. The driven tube contained atmospheric air, and was separated from the driver tube by a $0.381 \mathrm{~mm}$ (0.015 in) thick mylar diaphragm. Thin mylar could be used since the initial pressures were low and the post detonation pressure is typically about 20 times the initial level. Subsequent tests increased the initial detonation tube pressure to 8 atm. Both upstream and downstream-propagation modes were examined. A typical detonation tube pressure trace for the upstream-propagation mode is shown in Fig. 5 for an initial detonation tube pressure of $6 \mathrm{~atm}$. The sensor closest to the igniter (location 4) detects some pre-compression ahead of the detonation wave. This is an indication that the detonation wave has not reached full $\mathrm{C}-\mathrm{J}$ velocity. The pre-compression phenomena was observed in experiments reported by Helman ${ }^{12}$, and was also observed in our own experiments with a smaller detonation tube being used for pulse detonation engine research $^{13}$. The next sensor passed by the detonation wave (location 3) as well as subsequent sensors (not shown in Fig. 5 for clarity) do not detect any pre-compression, and the time of flight calculations indicate the detonation wave has reached $\mathrm{C}-\mathrm{J}$ velocity. A similar plot for the downstream-propagation mode is shown in Fig. 6 for an initial pressure of 6 atm. The time of flight measurements indicate $\mathrm{C}-\mathrm{J}$ velocity was achieved by the time the detonation wave reached the first pressure sensor. The rapid fall-off in pressure following passage of the detonation wave for both cases is due the Taylor rarefaction wave that follows the incident detonation wave ${ }^{13}$.
The overall performance map of the modified shock tube was obtained by conducting a parametric variation of both driver and driven tube pressures, and by introducing varying amounts of helium dilution. Test results are summarized in Figs. 7. The performance was considerably less than predicted. Furthermore, contrary to expectations, the data indicated that the downstream ignition location provided better performance. An analysis of the test data, coupled with experience gained from basic detonation wave experiments conducted as part of a Pulse Detonation Wave Engine (PDE) development program ${ }^{13}$, suggest the following reasons for the low performance. Fig. 1 illustrates the wave process for the downstream-propagation mode of operation, resulting from ignition of the detonable mixture at the upstream end of the detonation tube. The incident detonation wave is followed by a strong expansion wave that is generated to satisfy the zero velocity boundary condition at the closed end of the tube. This expansion wave causes an immediate drop in pressure from the Chapman-Jouguet level generated by the incident detonation wave, as shown in Fig. 5, and the interaction of this expansion wave with the reflected detonation wave appears to drastically lower the pressure level behind the reflected detonation wave. It is this pressure that initiates and sustains the incident shock wave propagation in the driven tube, and consequently very rapid attenuation of the incident shock wave is suspected.

A different cause is suspected for the reduced performance with the upstream-propagation mode of operation. Fig. 6 shows a typical pressure trace in the detonation tube for this mode. A detailed analysis of the pressure data indicates that the initial wave formation is a weak detonation wave (MO 1.7) that transitions to a fully-developed $\mathrm{CJ}$ detonation wave $\left(M_{D}-5.3\right)$ about $50 \mathrm{~cm}$ (20 inch) from the ignition source, which is consistent with results observed in the PDE experiments ${ }^{13}$. Fig. 8 shows an end-wall pressure trace from a similar test conducted as part of the PDE program. This data was from a $7.62 \mathrm{~cm}$ (3 in) diameter chamber containing a stoichiometric mixture of hydrogen and oxygen, initially at a pressure level of 1 atm. Transition to a fully developed CJ detonation wave for this case was triggered by a Shchelkin spiral $1^{14}$ inserted into the detonation chamber, but similar results have been observed for cases at higher initial pressure or with different fuels which naturally transitioned to $\mathrm{CJ}$ detonation wave propagation speeds without turbulence 
enhancement. The end-wall pressure is seen to gradually increase to a level of about 70 psia, and then abruptly increase to a level of about 110 psia, corresponding to the transition in wave propagation from a weak to a $\mathrm{CJ}$ detonation wave. This pressure level is in close agreement with the predicted end-wall pressure using the Zeldovichvon Neumann-Doring (ZND) detonation model ${ }^{15}$, but the fact that a $C J$ wave does not form immediately upon ignition probably interferes with the formation of a strong incident shock wave in the driven tube.

\section{Detonation Driver Modifications}

The reduced performance of the detonation-driven shock tube prevented attainment of the shock Mach numbers required to meet the original goals of the program. After evaluation of several proposed options for upgrading the shock tube performance, we elected to adopt the shockinduced mode of detonation being incorporated by Bakos, et.al. ${ }^{16}$ of GASL to expand the performance of their HYPULSE facility. The concept is illustrated in Fig. 9 (adapted from Ref. 16) in which a high pressure air or helium driver is placed upstream of the detonation tube and used to drive a shock wave into the detonation tube. This shock wave should quickly transition to a $\mathrm{CJ}$ detonation wave. However, the expansion of the high-pressure gas from the driver tube drastically reduces or may even eliminate the Taylor rarefaction wave that follows the incident detonation wave in the arc-induced detonation mode (Fig. 1), resulting in a much higher pressure level behind the detonation wave. In fact, in the "perfectly-driven" mode, the full CJ pressure level can ideally be maintained behind the detonation wave, as shown in Fig. 10 (from Ref. 16).

The necessary modifications were implemented by reconfiguring the detonation driver tube back to its original pressure-driven mode of operation, and converting one of the original $8.23 \mathrm{~m}$ (9 ft), 15.24 $\mathrm{cm}$ (6 in) diameter driven-tube sections to become the detonation tube section. The original doublediaphragm section was reinstalled between the upstream driver tube and the detonation tube, and the $4.12 \mathrm{~cm}$ (1.62 in) diameter driven tube was shortened to a length of $3 \mathrm{~m}(10 \mathrm{ft})$ to reduce shock attenuation due to boundary layer growth behind the incident shock. The new detonation tube was also modified to allow insertion of four pressure transducers to monitor the detonation wave development.
Test Results from Shock-Induced Detonation Mode

A typical detonation tube pressure trace from the shock-induced mode is shown in Fig. 11. The initial conditions in the detonation tube were a stoichiometric mixture of hydrogen and oxygen at an initial pressure of 4 atm. Air at a pressure of $217 \mathrm{~atm}$ was loaded into the upstream driver tube. The time-of-flight measurements indicate a detonation wave propagation speed of $2920 \mathrm{~m} / \mathrm{s}$, which is almost identical to the theoretical $\mathrm{CJ}$ detonation wave speed for these conditions. This particular test corresponded to the under-driven mode (Fig. 10). For this mode, the incident detonation wave is followed by a moderatestrength Taylor rarefaction wave that lowers the pressure. The reflected detonation wave increases the pressure by a factor of about 2.3, which is in good agreement with theoretical considerations. Unfortunately, the reduction in pressure caused by the rarefaction wave lowers the peak pressure behind the reflected detonation wave, although not as much as observed for the arc-initiated detonation wave. The pressure trace in the driven tube for this test is shown in Fig. 12. The time-of-flight measurements indicate a shock Mach number of 5.95 .

Test results from two runs comparing air and helium drivers at nominal driver tube pressures on the order of $210 \mathrm{~atm}$ are shown in Figs. 13-14. The detonation tube contained a stoichiometric mixture of hydrogen and oxygen at a pressure of $1.5 \mathrm{~atm}$, and the initial pressure in the driven tube was nominally $0.14 \mathrm{~atm}$. The run shown in Fig. 13 is typical of the under-driven mode, and is characterized by the drop in pressure through the Taylor rarefaction wave. In contrast, the test shown in Fig. 14 is nearly perfectly driven, and the pressure drop through the Taylor rarefaction wave was reduced considerably. Furthermore, the pressure level achieved by the reflected detonation wave is much higher, and the corresponding driven-tube Mach number is increased from 6.70 to 7.65 . Thus it appears that the shock-induced detonation mode offers substantial gains in performance by reduction or possible elimination of the Taylor rarefaction wave.

The composite performance map obtained to date is shown in Fig. 15. The peak shock Mach number obtained with the air driver was 10.71 , resulting in a post-shock temperature and pressure of $4190 \mathrm{~K}$ and $9.8 \mathrm{~atm}$, respectively. The highest post-shock 
pressure attained with the air driver was 21 atm, with a corresponding temperature of $2058 \mathrm{~K}$. Use of helium in the upstream driver resulted in considerable improvement in performance, as anticipated, generally causing an increase in both temperature and pressure over that attainable with the air driver for comparable conditions. Comparing Figs. 15 and 7 show that a significant enhancement in shock tube performance was realized by incorporation of the shock-induced detonation mode, over that attainable with the arcinitiated detonation.

\section{Predicted Shock Tunnel Performance Improvement with Detonation Driver}

Following completion of the current test program, we plan to re-convert the facility to a shock tunnel configuration, but retain the shock-induced detonation driver. Estimates of the anticipated performance improvement are shown in Fig. 16. The increased enthalpy level resulting from use of the detonation driver substantially increases the Reynolds number capability, particularly at higher Mach numbers.

\section{Concluding Remarks}

The conversion of the existing pressure-driven shock tunnel to a detonation-driven shock lube provided a useful test facility for investigating the electrical characteristics of high-pressure seeded plasmas. The performance of the facility with the original arc ignition mode was considerably lower than predictions based on ideal shock and detonation wave models. This reduced performance was shown to be a result of the interaction between the Taylor rarefaction wave and the reflected shock wave for the downstream propagation mode of operation. For the upstream mode, the gradual rise in end-wall pressure resulting from the failure to directly initiate a Chapman-Jouguet detonation wave is the most likely cause of the lower performance. Furthermore, in this mode, the initial flow behind the incident detonation wave is in the upstream direction; thus a stronger expansion wave is required to reverse the direction of flow.

Implementation of the shock-induced detonation mode provided a considerable increase in performance. Peak shock Mach numbers of 10.7 have been achieved to date. Furthermore, by proper tailoring of conditions, it is possible to eliminate the trailing Taylor rarefaction wave associated with the arc ignition mode. In effect, the driver tube exhaust acts like a "gas piston" to sustain the pressure behind the incident detonation wave.

The shock-induced detonation driver concept has far-reaching potential for improving shock tube and shock tunnel performance at reasonable capital investment. Performance estimates for the UTA shock tunnel operated with a shockinduced detonation driver show considerable improvement over that attainable with the original cold gas driver.

\section{Acknowledgements}

The detonation-driven shock tube facility development was supported by MSE, Inc. through Contract No. 96-C323-F, monitored by Dr. Y. M. Lee and Mr. Gloyd Simmons. We are indebted to Drs. Robert Bakos and John Erdos of GASL for many helpful discussions concerning the shockinduced detonation mode of operation. Also, valuable suggestions from Dr. Dave Bogdanoff of Eloret-Thermal Sciences Institute are gratefully acknowledged. Finally, we acknowledge the contribution of Mr. Dennis Bushnell of NASALangley Research Center, who initially suggested that we explore the detonation driver concept.

\section{$\underline{\text { References }}$}

${ }^{1}$ Lin, S. C., Resler, E. L., and Kantrowitz, A., "Electrical Conductivity of Highly lonized Argon Produced by Shock Waves," Journal of Applied Physics, Vol. 26, No. 1, Jan. 1953, p. 95.

${ }^{2}$ Garrison, G. W., "Electrical Conductivity of a Seeded Nitrogen Plasma," AIAA Journal, Vol. 6, No. 7, July 1968, pp. 1264-1270.

3"Proceedings of the Magnetohydrodynamics (MHD) Technical Review and Planning Workshop," NASA, Washington, D.C., February 1995.

${ }^{4 " S u m m a r y}$ of Capabilities of Hypersonic Shock Tunnels at Calspan ATC," Calspan Advanced Technology Center, Buffalo, NY.

${ }^{5}$ Stalker, R. J. "Shock Tunnels for Real Gas Hypersonics," in Aerodynamics of Hypersonic Lifting Vehicles, AGARD CP-428, Nov. 1987.

${ }^{6}$ Lee, B.H.K., "Detonation Driven Shocks in a Shock Tube," AIAA Journal, Vol. 5, No.4, April 1967, pp. 791-792.

${ }^{7}$ Yu, H.R., Esser, B., Lenartz, M. and Gronig, H., "Gaseous Detonation Driver for a Shock Tunnel, " Shock Waves, Vol. 2, 1992, pp. 245-254.

${ }^{8}$ Tagno, J., Calleja, J. and Erdos, J., 
"Exploratory Tests of Detonation-Driven Expansion Tube Performance," NASA CR191580, General Applied Sciences Laboratory, Ronkonkoma, NY, March 1994.

${ }^{9}$ Gordon, S. and McBride, B. J., " Computer Program for Calculation of Complex Chemical Equilibrium Composition, Rocket Performance, Incident and Reflected Shocks, and ChapmanJouguet Detonations," NASA SP-273, 1976.

${ }^{10}$ Angelone, J.P., "Shock Tube-High Temperature Gasdynamics Studies," M.S. Thesis, The University of Texas at Arlington, 1978.

${ }^{11}$ Stuessy, W.S., Murtugudde, R.G., Lu, F.K. and Wilson, D.R., "Development of the UTA Hypersonic Shock Tunnel," AIAA Paper 90-0090, 1990.

12 Helman, D., Shreeve, R. P, and Eidelman, S., "Detonation Pulse Engine," AlAA Paper 86-1683, 1986.

${ }^{13}$ Stanley, S.B., Stuessy, W.S. and Wilson, D.R., "Experimental Investigation of Pulse Detonation Wave Phenomena," AIAA Paper 952197, 1995.

${ }^{14}$ Shchelkin, K. I., Soviet Journal of Technical Physics, vol 10, 1940, pp. 823-827.

${ }^{15}$ Bussing, T. and Pappas, G., "An Introduction to Pulse Detonation Engines," AIAA Paper 940263, 1994.

${ }^{16}$ Bakos, R. J., Castrogiovanni, A., Calleja, J. F., Nucci, L. and Erdos, J. I., "Expansion of the Scramjet Ground Test Envelope of the HYPULSE Facility," AIAA Paper 96-4506, 1996.

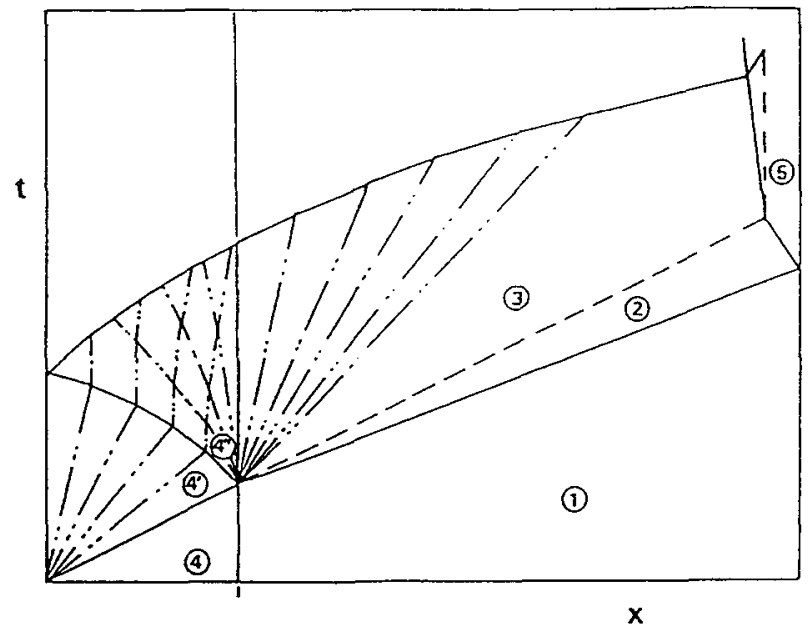

Fig. 1 Wave diagram for detonation-driven shock tube, downstream-propagation mode of operation

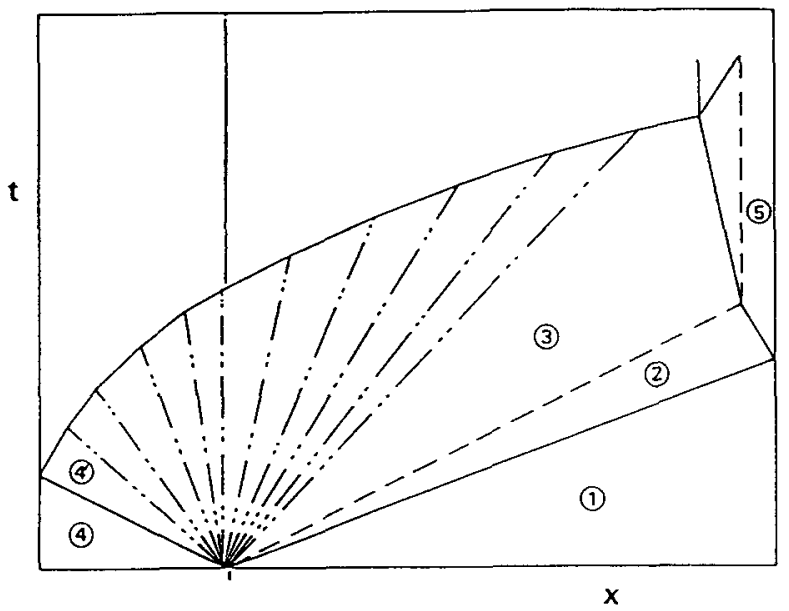

Fig. 2 Wave diagram for detonation-driven shock tube, upstream-propagation mode of operation

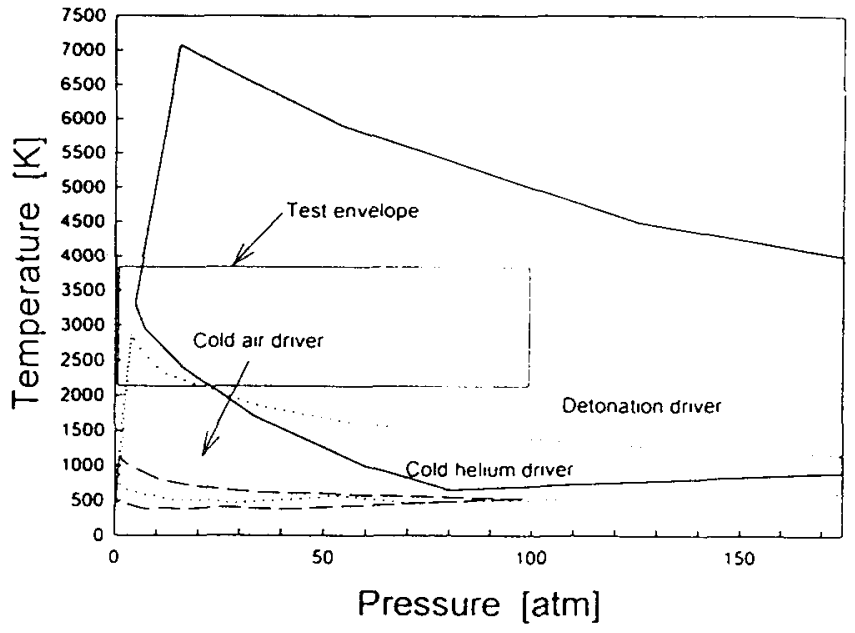

Fig. 3 Predicted performance map, downstream-propagation mode

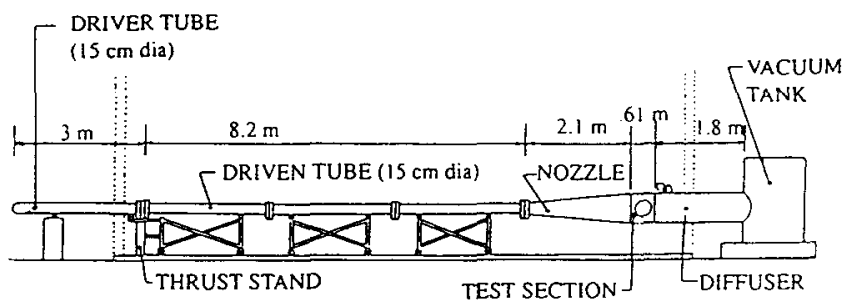

Fig. 4 Elevation view - existing hypersonic shock tunnel 


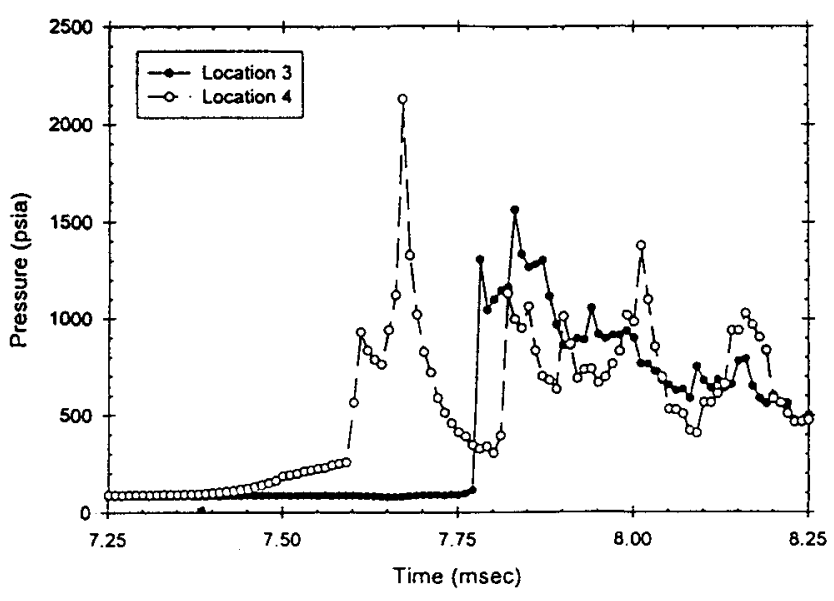

Fig. 5 Detonation tube pressure traces, upstream mode at an initial pressure of $6 \mathrm{~atm}$, electric arc-ignition

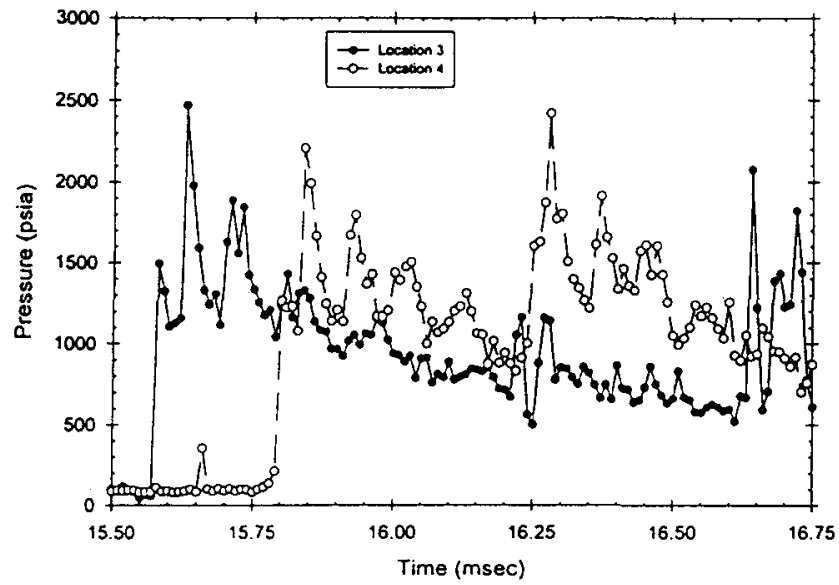

Fig. 6 Detonation tube pressure traces, downstream mode at an initial pressure of $6 \mathrm{~atm}$, electric arc-ignition

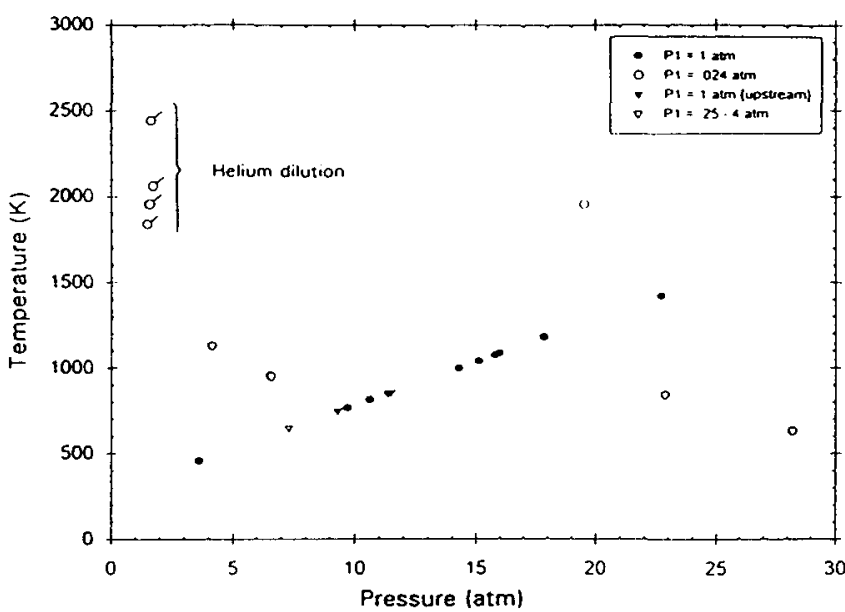

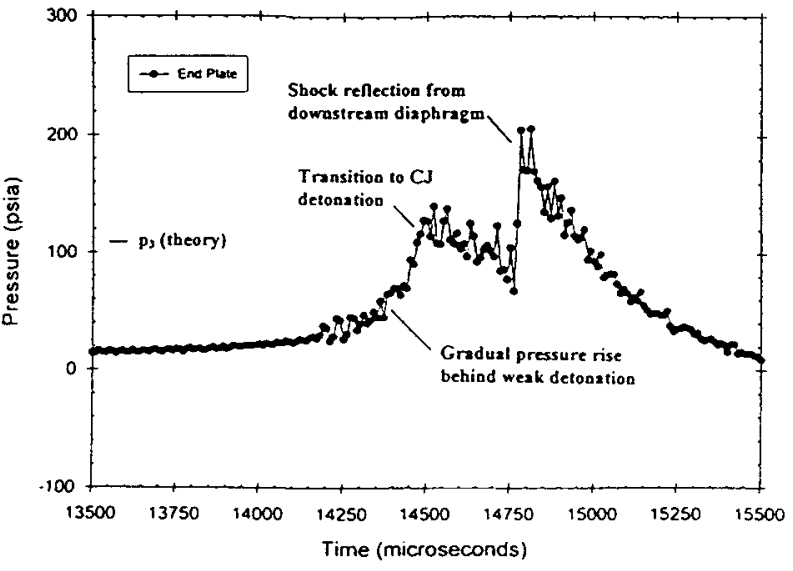

Fig. 8 End wall pressure trace from PDE experiment

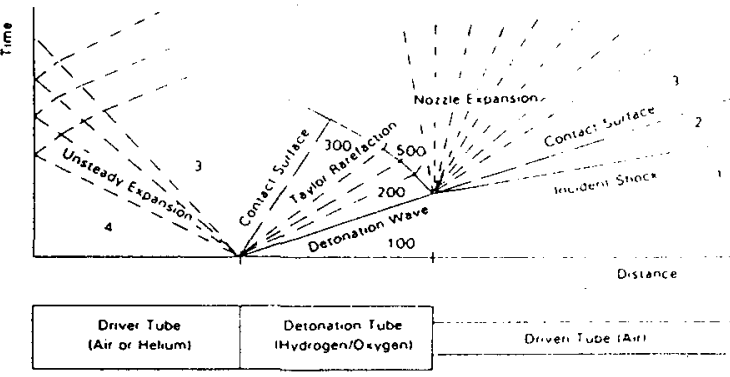

Fig. 9 Shock-induced detonation driver concept (from. Ref. 16)

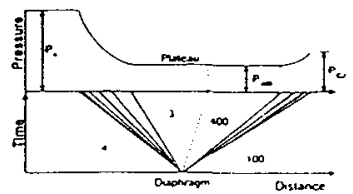

Under-Driven

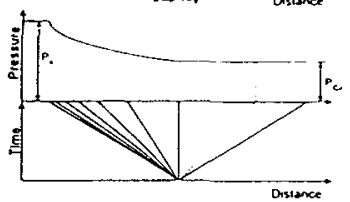

Perfectly-Driven

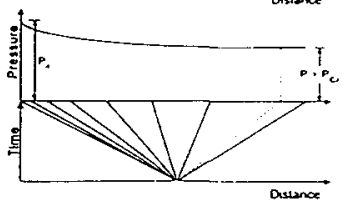

Over-Driven

Fig. 10 Shock-induced detonation driver operational modes (from Ref. 16)

Fig. 7 Experimental performance map, electric arc-ignition 


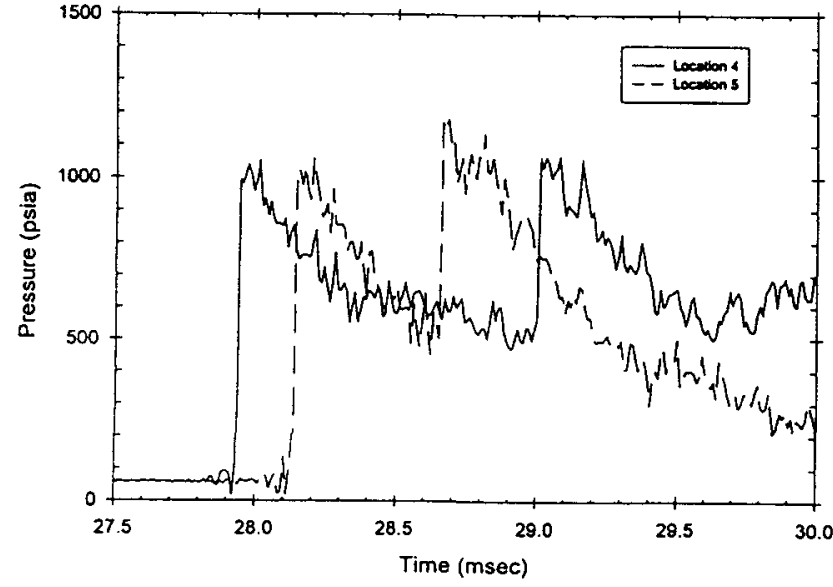

Fig. 11 Detonation tube pressure traces for an initial detonation tube pressure of 4 atm, shock-induced detonation (air driver pressure $=217 \mathrm{~atm}$ )

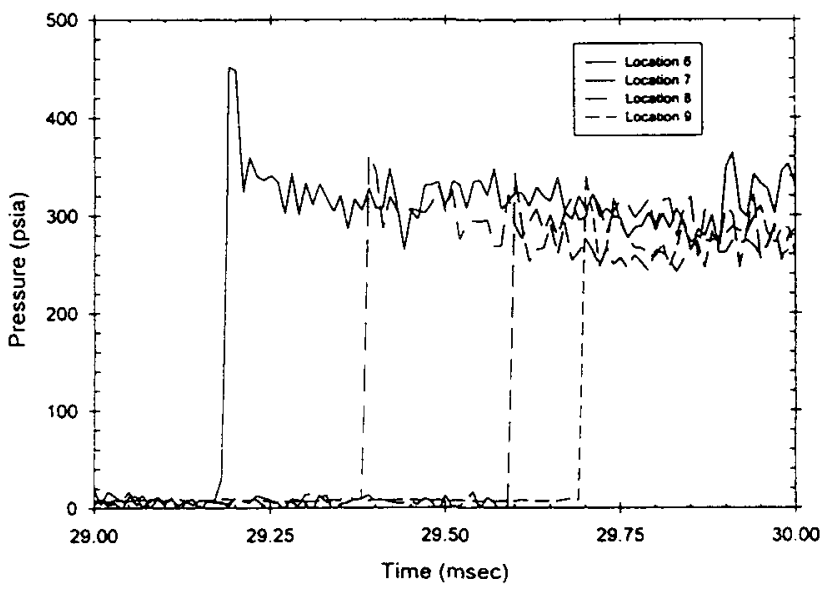

Fig. 12 Driven-tube pressure traces for an initial detonation tube pressure of 4 atm, shock-induced detonation (air driver pressure $=217 \mathrm{~atm}$ )

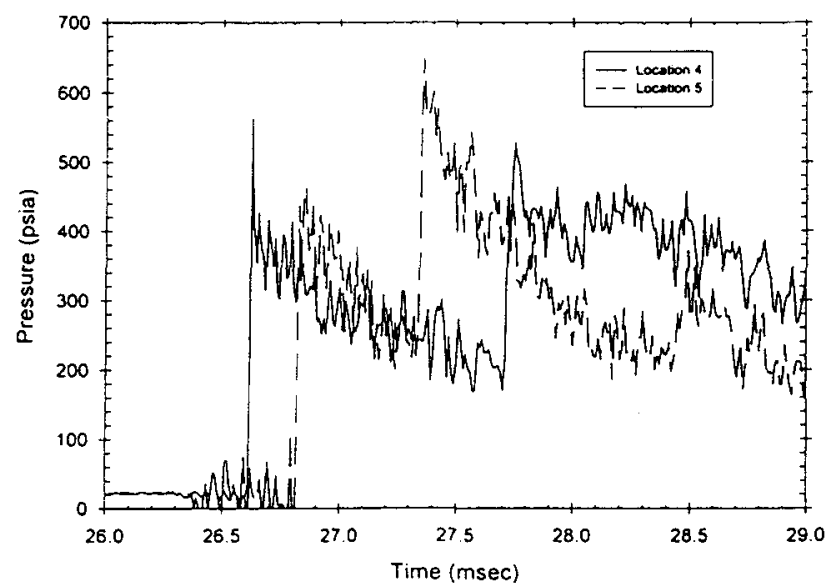

Fig. 13 Detonation tube pressure traces for an initial detonation tube pressure of $\mathbf{1 . 5}$ atm, shock-induced detonation (air driver pressure $\mathbf{2 1 9} \mathbf{a t m}$ )

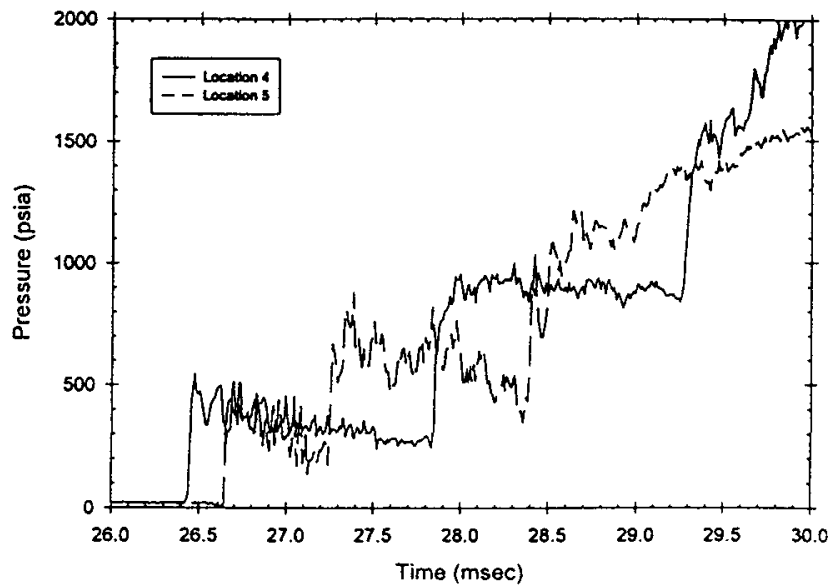

Fig. 14 Detonation tube pressure traces for an initial detonation tube pressure of $1.5 \mathrm{~atm}$, shock-induced detonation (helium driver pressure $\mathbf{2} 201 \mathrm{~atm}$ )

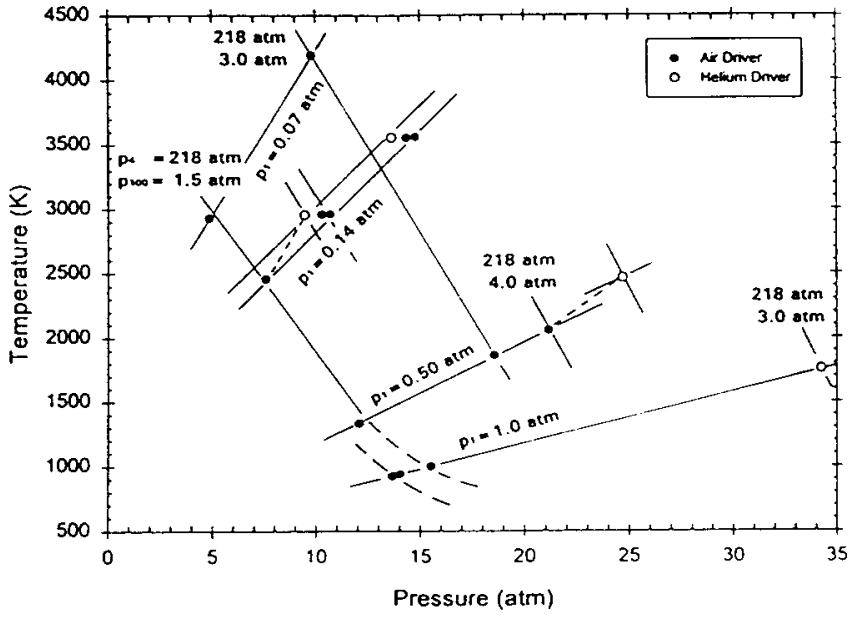

Fig. 15 Experimental performance map, shockinduced detonation

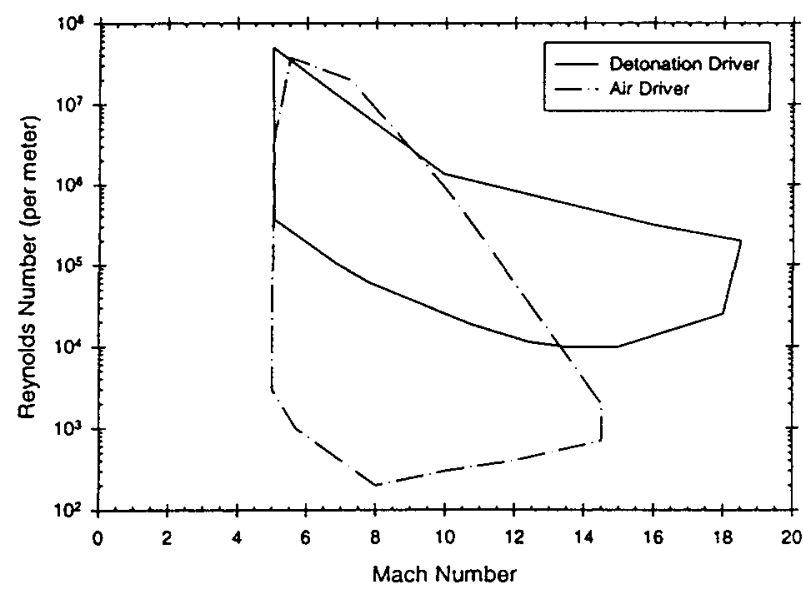

Fig. 16 Predicted reflected shock tunnel performance enhancement with shockinduced detonation driver 